\title{
1945- 1969: Transformações sistêmicas e a reação da política externa brasileira
}

1945- 1969: Systemic transformations and the reaction of the Brazilian Foreign Policy

\section{José Késsio Floro Lemos ${ }^{1}$}

\begin{abstract}
RESUMO
O presente artigo busca analisar as mudanças na política externa brasileira mediante as inflexões ocorridas no sistema internacional entre os anos de 1945 e 1969. Foi possível constatar que a pluralização das possibilidades com a ascensão de novos atores internacionais nos deu a oportunidade de incorporar os princípios de autonomia e universalização na pauta de nossa política externa.
\end{abstract}

Palavras-chave: Brasil; Política Externa; Sistema Internacional

\begin{abstract}
The present paper seeks to analyze the Brazilian foreign policy reactions by inflections occurred in the international system between the years 1945 and 1969. It was found that the pluralization of the possibilities with the rise of international actors gave us an opportunity to incorporate the principles of autonomy and universality in our foreign policy agenda.
\end{abstract}

Key-words: Brazil; Foreign Policy; International System.

\section{INTRODUÇÃO}

A década de 1960 representou um divisor de águas na Política Externa brasileira. As modificações na estrutura da bipolaridade da Guerra Fria, bem como no contexto interno do país, foram de oportuna importância na fomentação de novas diretrizes para nossa diplomacia. Sendo assim, inicialmente, valem ser descritas algumas características da conjuntura internacional do período.

No âmago do polo soviético, a URSS estalinista se reinventou sob a liderança de Nikita Khrushchev. Conforme dito por Melo e Silva, "além de promover um início de uma liberalização interna chamada desestalinização", o líder soviético "procurou deslocar o conflito entre as superpotências do plano puramente militar para as áreas econômica e tecnológica" (Melo \& Silva, 1992, p.213). Não obstante, um intenso movimento de descolonização na África e na Ásia trouxe ao sistema internacional novos e afervorados players. A ascensão e o fortalecimento dos países não desenvolvidos trouxeram uma

\footnotetext{
${ }^{1}$ Graduando em Relações Internacionais pela Universidade Estadual da Paraíba - João Pessoa, Paraíba, Brasil. 
maior maleabilidade à típica rigidez da Guerra Fria. Portanto, nesse momento, emergentes estavam surgindo, o Sul insatisfeito estava se movimentado e a URSS estava mais flexível politicamente. Tal movimento no fluxo da política mundial acabou por criar novas formas de relacionamento entre os Estados.

Na América, a tentativa dos Estados Unidos de forçar a liberalização das economias dos países latino-americanos começou a ser questionada. A solidariedade política e a dependência econômica passaram a se transformar em um sentimento de descontentamento. Ou seja, a

[...] postura norte americana [...] direcionava-se claramente no sentido de perpetuar um padrão de relacionamento econômico totalmente assimétrico, no qual as economias latino-americanas deveriam se manter basicamente como fornecedoras de matérias primas necessárias ao consumo doméstico e à produção industrial americana [...] (MELLO \& SILVA, 2014, p. 213).

Deste modo, Melo \& Silva (1992) afirma que a insatisfação que permeava o continente acabou sendo expressa na criação da Comissão Econômica para a América Latina (CEPAL) (MELLO \& SILVA, 2014). Ademais as oportunidades abertas com a flexibilização no sistema internacional iriam despertar no Brasil, e em outros países não desenvolvidos, o desejo de diversificar as relações políticas e econômicas de acordo com as preferências e necessidades particulares. Nesses termos, a década de 60, no Brasil, seria marcada pela maturação de uma política externa baseada nos preceitos de autonomia e de defesa do interesse nacional.

\section{Brasil e EUA na Ordem Internacional: 1945-1958}

Ao término da $2^{\text {a }}$ Guerra Mundial os Estados Unidos da América tornou-se a nação mais rica e poderosa do mundo. Todavia, o objetivo inicial dos americanos de fomentar o comércio para gerar o desenvolvimento iria ser sufocado pela Guerra Fria e a necessidade de combater o comunismo soviético. Ou seja, as prioridades foram mudadas. A pauta da segurança, naquele momento, sobrepunha-se, de certo modo, à pauta econômica. Consequentemente, "na primeira metade do século XX, a política externa brasileira teve como tendência predominante a inserção do país no contexto hemisférico onde o eixo principal era a relação com os Estados Unidos" (VIZENTINI, 2013, p.30). Até o fim da década de 1950, "as relações exteriores do Brasil voltaram-se 
prioritariamente para os Estados Unidos, em busca de status de aliado privilegiado" (VIZENTINI, 2013, p.11). Entretanto, a alteração do foco americano e a escassez de seus investimentos nos países não desenvolvidos, acabou despertando uma ala de insatisfeitos.

A Conferência de Bangung (1955) apresentou ao mundo o desagrado dos países periféricos mediante a conjuntura internacional (Charles Sidarta, 2008). O ensejo por um sistema mais plural e democrático permeou as expectativas de tais países. No Brasil não foi diferente. Na medida em que a relação com os EUA mostrava-se insuficiente para as necessidades industriais que o país detinha, a política externa brasileira viu-se cercada pela necessidade de alterar seu perfil. Deste modo, a autonomia da dependência de Vargas "e o nacionalismo dos governos populistas dos anos 1950, representaram uma estratégia de barganha em relação à Washington" (VIZENTINI, 2013, p. 11).

Diante dessa realidade, em 1958, Juscelino Kubitschek lança a Operação Panamericana. Para Oliveira (2005), a OPA “representou uma estratégia de sensibilizar os Estados Unidos para a problemática do subdesenvolvimento brasileiro e regional, com vistas a que houvesse um redirecionamento dos investimentos norte-americanos para o Brasil [...]" (OLIVEIRA, 2005, p. 84). Ademais, para Melo \& Silva, a OPA “é apresentada como uma espécie de 'antessala' da 'política externa independente' de Jânio Quadros e João Goulart" (MELLO e SILVA, 1992, p. 209). Tal afirmação parte do fato de que houve uma ampliação da agenda econômica externa do país. Esta iniciativa objetivava uma maior afirmação do Brasil tanto no âmbito interno como no externo. Outrossim, o tema multilateralismo foi reintroduzido à pauta da política externa, haja vista que ela fazia "associação entre a segurança, a democracia e o desenvolvimento econômico" (OLIVEIRA, 2005, p. 84). Entretanto, segundo Oliveira (2005), a OPA não significou uma ruptura da política externa brasileira.

A OPA manteve o raio de atuação da nossa diplomacia dentro do hemisfério norte americano. Oliveira também afirma que o que a OPA trouxe de novidade, naquele momento, foi "uma revisão do relacionamento tradicional com vistas a maior inserção no campo econômico e a maior participação norte-americana nos projetos de desenvolvimento regional" (OLIVEIRA, 2005, p. 86). De qualquer forma, o terreno agora estava preparado para receber as mudanças tão almejadas pela política externa brasileira. 


\section{A Política Externa Independente}

No ano de 1961 Jânio Quadros chega à presidência da República. Junto com ele chega a materialização do desejo de ser pôr em prática uma nova política externa. No âmbito econômico o desenvolvimento vira a tônica. Diante de um sistema e de uma conjuntura que não oferecia perspectiva de desenvolvimento, restava ao país buscar novas coordenadas geográficas para suas relações econômicas. Esse caminho percorria o viés de um progressivo distanciamento em relação aos Estados Unidos. Não era um divórcio litigioso, mas uma separação minimamente amigável em direção a uma maior autonomia. Esse novo caminho ganhou veemência depois da frustrada tentativa de Juscelino Kubitschek - através da OPA - de estabelecer com EUA uma aproximação que satisfizesse também aos anseios do Estado brasileiro. Portanto,

[...] como a OPA não conseguiu viabilizar a participação norte-americana no processo de desenvolvimento brasileiro, cristalizou-se a percepção de que a manutenção do ideário de uma relação especial com os Estados Unidos era totalmente inviável. (OLIVEIRA, 2005, p. 87-88).

Segundo Vizentini (2008), a PEI de Jânio Quadros estava ancorada em cinco princípios: 1) Exportações brasileiras para todos os países, inclusive socialistas; 2) Defesa do Direito Internacional, da autodeterminação e da não-intervenção nos assuntos internos dos outros países; 3) Política da paz, desarmamento e coexistência pacífica nas Relações Internacionais; 4) Apoio à descolonização completa de todos os territórios ainda submetidos; 5) Formulação autônoma de planos nacionais de desenvolvimento de ajuda externa (VIZENTINI, 2008, p.23).

Guiado pelos princípios acima descritos, Jânio também "buscou inspiração no nacionalismo do presidente francês Charles de Gaulle, que buscava autonomia para a França dentro da Aliança Ocidental" (VIZENTINI, 2008, p.23). Ademais, reatou relações diplomáticas com a URSS e com outros países do leste europeu (VIZENTINI, 2008, p.23). Desta forma, a Política Externa Independente ganha suas primeiras diretrizes práticas. Mais do que isso, o comportamento da PEI estava aportado em duas sólidas premissas: autonomia e universalização. Esta, refere-se à diversificação das nossas parceiras. Aquela, aponta para a expectativa de uma política externa sempre em busca do interesse nacional. De acordo com as próprias palavras de Jânio: “a política externa de uma nação, 
em si, deve ser a corporificação dos ideais e interesses comuns que governam sua existência" (FRANCO, 2007, p.146). Todavia, para Oliveira (2005), a PEI, naquele momento, "apresentava-se muito mais como uma intenção, um discurso, que atingiria sua maior capacidade de ação, e implementação, no Governo general Geisel, na metade dos anos 1970" (OLIVEIRA, 2005, p. 88).

No âmbito interno, a instabilidade correu a sustentação do governo Jânio. Politicamente o Brasil estava dividido; divisão esta que foi agudizada mediante a aproximação do presidente com figuras alinhadas com o polo comunista (FRANCHINI NETO, 2005). A condecoração de Che Guevara culminou com eclosão de uma crise, expressa na renúncia de Jânio Quadros em 25 de agosto de 1961. 0 contra-ataque da direita civil e militar acabou impossibilitando até mesmo a posse do vice-presidente João Goulart, que estava em uma missão diplomática na República Popular da China. 0 Rápido governo Jânio inaugurou a primeira fase de uma política externa independente, "cuja marca principal foi a busca pela preservação da paz, aproveitando-se do poder de barganha decorrente da possibilidade do país optar por uma postura neutralista"2. 0 preço pago por essa política foi alto, e por pouco, a crise desencadeada não culminou com um golpe militar, que na verdade, apenas havia sido adiado.

Contudo, uma crise institucional estava estabelecida. Os militares e as forças conservadoras não admitiam que o esquerdista João Goulart ficasse no poder. Sua posse só foi aceita após uma manobra realizada no Congresso, onde foi estabelecido o Parlamentarismo no país. A Constituição de 1946 foi, então, reformada, reduzindo-se os poderes do presidente em favor de um gabinete ministerial chefiado por um primeiro ministro. Segundo Vizentini (2008), o regime parlamentarista enfraqueceu a presidência e o processo decisório. Em 1963, com o retorno do presidencialismo, o governo em Washington subiu o nível de alerta.

O fim do regime parlamentar era visto como a perca de "uma garantia limitadora à ação de um governo considerado de esquerda" (VIZENTINI, 2008, p. 27). Vizentini também aponta que a revolução cubana em 1962, agravou a preocupação dos americanos com o surgimento de uma "nova Cuba", agora de proporções continentais. A CIA e o governo americano, portanto, passam a agir diretamente para o

\footnotetext{
${ }^{2}$ MELLO \& SILVA. O Brasil de JK > A política externa no cenário da Guerra Fria. Disponível em: http://cpdoc.fgv.br/producao/dossies/JK/artigos/PoliticaExterna/CenarioGuerraFria. Acesso em 16 de Novembro de 2014.
} 
enfraquecimento político de Jango. 0 Comício na Central do Brasil e a marcha da família com Deus maximizaram as tensões à níveis insustentáveis, o que acabou culminando no golpe militar de 31 de março de 1964.

\section{A Política externa no governo militar}

Ano de 1964. Ao som dos tambores da conspiração e sob o respaldo dos canhões, os militares chegam ao poder. Uma década após o suicídio de Getúlio Vargas, seus herdeiros - Leonel Brizola e João Goulart - haviam sido superados. Chamada por seus defensores de "Revolução", o regime militar seria marcado pela ruptura do regime democrático, por forte centralismo e autoritarismo, pela cassação dos direitos políticos de opositores e pela violação das liberdades individuais. Os motivos oficiais para o desfecho do Golpe de 1964 eram o espectro do comunismo, a crise político-econômica e a corrupção. (BUENO, 2010). Deste modo, o governo militar assume com duas propostas claras: evitar uma "socialização" do país e recuperar a econômica através da retomada do desenvolvimento.

Em termos de política externa, o início do governo militar acabaria sendo marcado por um grande paradoxo. Isso porque, para a consolidação de uma Política Externa Independente, as estruturas internas e externas da política brasileira precisariam estar em uma relativa sincronia. Porém, o que víamos na verdade, era um desajuste proveniente de um conflito político interno. De um lado, acreditava-se que o desenvolvimento nacional viria pelo estreitamento das relações com a potência do Norte. Já outros, acreditavam que em termos de desenvolvimento, essa estratégia já não era suficiente e que o Brasil precisava diversificar seu leque de parceiros. 0 que restou, a princípio, foi a intenção de Castelo Branco em descontinuar a PEI:

\footnotetext{
A política externa do Governo Castelo Branco caracteriza-se, inicialmente, pela descontinuidade da política externa independente desenvolvida pelos seus predecessores civis. Isso porque, como fundamento da nova postura, estava a crença de que a guerra fria constituía o elemento central da história contemporânea. A situação mundial encontrava-se, conforme esse pensamento, dividida em dois blocos antagônicos: o mundo democrático, ocidental, e o mundo colunista. (OLIVEIRA, 2005, p. 108).
}

Percebe-se, portanto, uma mudança substancial na centralidade da Política Externa Brasileira. A interdependência foi relevada mediante a valorização da Guerra 
Fria como fator preponderante no sistema internacional. Amado Cervo (1992, p.332), refere-se ao período como "um passo fora da cadência". Já Altemani, como a "política externa da interdependência". (OLIVEIRA, 2005, p.108). Para Vizentini, "o governo Castelo Branco representou um verdadeiro recuo, abandonando o terceiro-mundismo, o multilateralismo e a dimensão mundial da Política Externa Independente" (VIZENTINI, 2008, p.45). Ademais, Vizentini (2008) também afirma que tal comportamento representou um retrocesso tendo em vista que gerou uma aliança automática com os Estados Unidos, limitando nossas relações aos âmbitos hemisférico e bilateral.

Já no governo de Costa e Silva (1967-1969), os equívocos e o retrocesso cometidos por seu antecessor buscaram ser corrigidos. Agora, sob a liderança de um "linha-dura" o país volta-se ao modelo nacionalista de desenvolvimento. Segundo Vizentini (2008), as Relações Internacionais deste período "representaram uma ruptura profunda com o governo anterior, contrariando frontalmente Washington". (VIZENTINI, 2008, p. 45). Apensar de algumas diferenças, o foco no desenvolvimento e na autonomia delineava traços muito semelhantes à PEI. Naquele momento o governo brasileiro acreditava que a distensão "entre os Estados Unidos e a URSS fazia emergir o antagonismo Norte-Sul, opondo países ricos e pobres" (VIZENTINI, 2008, p. 45). Tal polarização procurou ser superada a partir da UNCTAD - Conferência das Nações Unidas sobre Comércio e Desenvolvimento, realizada em 1968. Nesta conferência, a política externa brasileira retorna ao quadro de referência Norte-Sul, voltando-se a se alinhar com as posições do $3^{\mathfrak{a}}$ mundo nas negociações de comércio e produtos de base.

Nesse contexto, a diplomacia da prosperidade de Costa e Silva realinhou os interesses do Brasil aos interesses do $3^{\text {a }}$ mundo, fazendo do país uma liderança nas negociações comerciais envolvendo os países subdesenvolvidos. Vemos, desta forma, que o dilema entre e o "desenvolvimento" e "poder" iria marcar a primeira etapa do governo militar brasileiro.

\section{Considerações Finais}


A análise histórica da Política Externa Brasileira nos conduz a um ponto marco para a mudança do perfil da nossa diplomacia. Apesar de todos os esforços de Getúlio Vagas no que concerne ao desatar dos laços de dependência econômica que marcavam as relações diplomáticas do Brasil, a conjuntura internacional do período não oferecia um oxigênio alternativo para a nossa sobrevivência. A Alternância entre alinhamento automático e o uso do poder de barganha conduziu a política externa brasileira por círculos relativamente previsíveis. A partir do governo de Juscelino Kubitschek e a Operação Pan-americana (OPA), as conjunturas interna e externa começaram a conspirar em favor dos interesses nacionais. A pluralização das possibilidades com a ascensão de novos atores nos deu a oportunidade de desancorar nossa existência dos preceitos e interesses americanos. A autonomia e a universalização na pauta de nossa política externa nos conduziram ao fortalecimento de uma Política Externa Independente. Tal fato começou a ser consolidado nos governos de Jânio Quadros e João Goulart.

A contestação do sistema vigente acabou ganhando eco à medida em que os países periféricos começaram a se articular, objetivando pressionar os países desenvolvidos a democratizar e pluralizar as beneficies do sistema econômico/comercial. No âmbito da ONU, a Comissão Econômica para a América Latina (CEPAL) foi estabelecida como um amplificador da insatisfação dos países não desenvolvidos. A conferência de Bangung (1955) e a criação do grupo de países não alinhados conduziram o sistema internacional a uma maior flexibilização. Ademais, o reerguimento econômico da Europa e do Japão também valem ser salientados como importantes fatores de contribuição no processo de flexibilização do sistema internacional.

Posto isto, a política externa brasileira encontrou na década de 1960 um terreno fértil para a germinação de seus interesses. Claro e evidente, que a disposição dos nossos policymakers também teve um papel substancial na modificação do nosso perfil diplomático. Mesmo mediante o retrocesso no governo Castelo Branco, os princípios da autodeterminação, defesa da soberania e da não-intervenção foram fundidos ao DNA da política externa nacional, de modo tal, que ainda hoje presenciamos tais características em nossa diplomacia. 


\section{REFERÊNCIAS}

BUENO, Eduardo. Brasil: uma História: cinco séculos de um país em construção. São Paulo: Leya, 2010.

CERVo, Amado Luiz \& BUENO, Clodoaldo. História da política exterior do Brasil. São Paulo: Ática, 1992.

CHARLES SIDARTA, Machado Domingos. A Política Externa Independente do governo João Goulart (1961-1964) ou momentos quentes de uma guerra fria. IN: Revista Escritas Curso de História de Araguaína, Vol. 1 (2008). Disponível em: <http://www.revista.uft.edu.br/index.php/escritas/article/view/1279>. Acesso em 25 Mai, 2015.

FRANCHINI NETO, Hélio. A Política Externa Independente em ação: a Conferência de Punta del Este de 1962. IN: Rev. bras. polít. int., Brasília, v.48, n. 2, p. 129151, Dec. 2005. Disponível

em: <http://www.scielo.br/scielo.php?script=sci_arttext\&pid=S0034$73292005000200007 \& \operatorname{lng}=e n \& n r m=i s o>$. acceso em 25 Mai, 2015.

MELLO e SILVA, Alexandra. "Desenvolvimento e Multilateralismo: Um estudo sobre a Operação Pan-Americana no contexto da política externa de JK". Contexto Internacional, 14 (2): 209-239, 1992.

MELLO e SILVA. O Brasil de JK > A política externa no cenário da Guerra Fria. Disponível em: http://cpdoc.fgv.br/producao/dossies/JK/artigos/PoliticaExterna/CenarioGuerraFria. Acesso em 16 de Novembro de 2014.

OLIVEIRA. Henrique Altemani de. Política Externa Brasileira. Editora Saraiva, 2005

QUADROS, Jânio. "Nova Política Externa do Brasil". IN: FRANCO, Álvaro da Costa. Documentos da Política Externa Independente. Brasília: Editora FUNAG, 2007.

VIZENTINI, Paulo Fagundes. A projeção internacional do Brasil 1930-2012. 3. Elsevier, 2013.

VIZENTINI, Paulo Fagundes. Relações Internacionais do Brasil: de Vargas a Lula. 3. Ed. São Paulo. Editora Fundação Perseu Abramo, 2008. 